\title{
CARACTERIZAÇÃO ESPAÇOTEMPORAL DE DUAS FLORESTAS ESTACIONAIS DO OESTE BAIANO, BARREIRAS-BA
}

\author{
SPATIO-TEMPORAL CHARACTERIZATION OF TWO SEASONAL FORESTS OF \\ WESTERN BAHIA, BARREIRAS-BA
}
CARACTERIZACIÓN ESPACIO-TIEMPO DE DOS BOSQUES ESTACIONALES
DEL OESTE DE BAHIA, BARREIRAS-BA

\author{
Daiany Caroline Joner - Universidade Federal da Bahia - Barreiras - Bahia - Brasil \\ daiany_joner@hotmail.com \\ Luci Ferreira Ribeiro - Universidade Federal da Bahia - Barreiras - Bahia - Brasil \\ luz.ribeiro@ufba.br \\ Pablo Santana Santos - Universidade Federal da Bahia - Barreiras - Bahia - Brasil \\ pablosantos@ufba.br
}

Resumo
Em estudos com fitofisionomias do Bioma Cerrado, as florestas estacionais estiveram entre as formações com
maior carência de estudo. Apesar do aumento expressivo de pesquisas nos últimos anos, elas se concentram
em estados do sul e sudeste brasileiro; já em boa parte do Cerrado nordestino, ainda há muitas lacunas no
conhecimento dos processos ecológicos que as envolvem. Este artigo tem como objetivo suprir parte dessa
deficiência ao descrever a estrutura espacial e a dinâmica da cobertura vegetal de duas florestas estacionais.
Ao longo da paisagem regional, essas fitofisionomias, em que estão restritas a eixos de drenagem próximos às
vertentes dos chapadões dominantes na região. Para a avaliação espaço-estrutural das duas fitofisionomias,
foram elaborados diagramas de perfis de vegetação e análise florística, já a dinâmica temporal foi observada
através do cálculo do Índice de Área Foliar (LAl) das estações chuvosa e seca usando como referência
imagens de satélite. Averiguou-se que as florestas estudadas possuem características estruturais e florísticas
diferenciadas, as quais têm papel fundamental na dinâmica temporal percebida pelo LAl, cujos índices são
semelhantes na estação chuvosa, distinguindo-se significativamente na estação seca. Este estudo demonstra
a importância dessas metodologias na definição de unidades da paisagem.
Palavras-chave: florestas estacionais, dinâmica espaçotemporal, semidecídua, decídua, sensoriamento remoto.

\section{Abstract}

In studies with physiognomies of the Cerrado Biome, seasonal forests were among the formations with greatest need of study. Although there is significant increase of research in recent years, they have focused on the southern and southeastern Brazil, while in much of the Northeast Cerrado, there are still many gaps in knowledge of ecological processes involving seasonal forests. This study aims to fill part of this deficiency in describing the spatial structure and dynamics of vegetation cover in two seasonal forests. Throughout the regional landscape these vegetation types are generally restricted to drainage lines near the dominant aspects of the plains in this region. For the assessment space of two vegetation types and structural diagrams were prepared profiles of vegetation and floristic analysis, while the temporal dynamics was observed by calculating the Leaf Area Index (LAI) of wet and dry seasons with reference to satellite imagery. It was found that the forests have studied structural and floristic differences, which play a fundamental role in the temporaldynamics perceived by the LAI, whose indices are similar in the rainy season, distinguishing itself significantly in the dry season. This study demonstrates the importance of these methodologies in the definition of landscape units.

Key words: seasonal forests, spatio-temporal dynamics, semideciduous, deciduous, remote sensing. 


\section{Resumen}

En estudios con fisonomías del Bioma Cerrado, bosques estacionales se encontraban entre las formaciones con mayor necesidad de estudio. Aunque hay un aumento significativo de la investigación en los últimos años, la mayor parte del noreste del Cerrado hay muchas lagunas en el conocimiento. Este estudio tiene por objeto cubrir parte de esta deficiencia en la descripción de la estructura espacial y la dinámica de la cubierta vegetal en dos bosques estacionales. A lo largo del paisaje regional estos tipos de vegetación se circunscriben a las líneas de drenaje de las llanuras de esta región. Para el espacio de la evaluación de dos tipos de vegetación y diagramas estructurales se prepararon perfiles de vegetación y análisis florístico, mientras que la dinámica temporal se observó mediante el cálculo del índice de área foliar (LAI) de las estaciones, con referencia a las imágenes satelitales. Se encontró que los bosques han estudiado las diferencias estructurales y florísticas, que desempeñan un papel fundamental en la dinámica temporal percibida por la LAI, cuyos índices son similares en la temporada de lluvias, distinguiéndose de manera significativa en la estación seca. Este estudio demuestra la importancia de estas metodologías en la definición de unidades de paisaje.

Palabras clave: bosques estacionales, dinámicaespacio-tiempo, semideciduo, decíduo, teledetección.

\section{Introdução}

O Cerrado é um dos biomas mais heterogêneos do Brasil, pois sua expressiva extensão territorial ao longo do país possibilita a existência de diferentes tipos de relevo, solo e clima, os quais têm influência direta sob a diversidade biológica verificada neste domínio (Felfili et al., 2005; Mueller e Martha Júnior, 2008).

Como reflexo da heterogeneidade, a vegetação que compõe o Cerrado é formada por um mosaico de fitofisionomias que variam entre formações campestres, savânicas e florestais (Eiten, 1972). A presença das florestas estacionais neste Bioma é resultante do processo dinâmico de expansão e retração da vegetação de áreas adjuntas da Amazônia, Mata Atlântica e Caatinga, que foi provocado pelas alterações climáticas ocorridas no passado (Aguiar, Machado, Marinho-Filho, 2004).

As florestas estacionais são denominadas como tal por estarem condicionadas à sazonalidade climática, sendo caracterizadas por diferentes níveis de caducifolia durante a estação seca (IBGE, 1992). Segundo Lopes (2007), há avanço significativo no conhecimento sobre as florestas secas no Brasil; no entanto, estes estudos estão mais concentrados nos estados de Minas Gerais, São Paulo e Rio Grande do Sul. Para Machado et al. (2008), os estudos no Bioma Cerrado ainda estão concentrados em centros associados às Instituições de Pesquisa como UnB, UFG, USP e UFMG e, portanto, existem várias lacunas de conhecimento em outras áreas, como exemplo, o Oeste da Bahia. Em um estudo elaborado por Ratter, Bridgewa- 
ter e Ribeiro (2003), foram identificadas oito regiões de Cerrado com flora similar, sendo uma delas o Oeste da Bahia.

Além de levantamentos florísticos, várias ferramentas são necessárias para a realização de estudos com florestas estacionais, de forma que englobe informações espaciais, estruturais e também temporais. Um instrumento útil para analisar a estrutura espacial da vegetação é o diagrama de perfil. Segundo Baker e Wilson (2000), o perfil representa a visualização completa da estratificação de uma determinada comunidade, sendo auxiliar em diversos estudos florísticos (Ramos, Pellens, Lemos, 2001). Somado a estes métodos realizados em campo, a utilização de técnicas de sensoriamento remoto tem sido amplamente difundida em áreas de Cerrado,tanto com o objetivo de monitorar como também de caracterizar os ciclos sazonais da vegetação através de imagens de satélite (Liesenberg, Ponzoni, Galvão, 2007).

O presente estudo teve como objetivo caracterizar de forma espaçotemporal duas florestas estacionais, semidecidual e decidual, localizadas em uma Reserva Legal de uma fazenda pertencente ao município de Barreiras no oeste da Bahia, as quais são tipicamente associadas a redes de drenagem dos chapadões presentes na região. Através disso, este trabalho também visa a suprir carências de estudos na região bem como construção de ferramentas que auxiliem na conservação do Bioma Cerrado.

\section{Área de estudo}

O estudo foi realizado na Reserva Legal da Fazenda Água Doce $\left(12^{\circ}\right.$ 12’05” S, 44 57’ 46” W), propriedade do grupo Antônio Balbino. A Reserva Legal possui aproximadamente 800 hectares e está localizada sete quilômetros a sudeste da sede do município de Barreiras-BA, em direção ao município vizinho Catolândia. A área da Reserva está situada na encosta sul da Serra do Mimo e possui altitude variando entre 500 a 630 metros. Sua vegetação, pertencente ao Bioma Cerrado, é composta por um mosaico de várias fitofisionomias, desde cerrado sensu strictu a florestas estacionais semidecidual e decidual. Segundo Reis,Vale e Lobão (2009), as florestas estacionais do Oeste da Bahia são encontradas em áreas restritas, ocupando os eixos de drenagem existentes nos patamares estruturais do chapadão que moldam o relevo aplanado da região. 
Geologicamente a Serra do Mimo é composta por formações Cretáceas que compõem a Bacia sedimentar Sanfranciscana e seu embasamento Proterozoico, representadas, no local, pelos arenitos do Grupo Urucuia e metassedimentos pelito-carbonáticos do Grupo Bambuí, respectivamente. Os arenitos compõem o topo dos peneplanos, formando escarpas verticais (Campos, Dardenne, 1997). Estas rochas possuem grande porosidade e, por isso, costumam formar expressivos aquíferos. Em virtude disso, nos vales escarpados, nascem diversos córregos que alimentam o Rio Grande.

A floresta estacional semidecidual analisada neste trabalho está associada às escarpas da Serra do Mimo, onde há pequenas drenagens convergidas pela topografia do chapadão. Além disso, seus solos possuem composição silto-arenosas com grande influência de matéria orgânica. Essas características favorecem o aumento de umidade e fertilidade desses solos. Já a floresta estacional decidual está situada em uma área mais plana, com solos menos drenados. O clima da área de estudo é classificado como AW, segundo Köppen, apresentando inverno seco e verão úmido. Segundo a média obtida, a partir dos dados registrados pela estação pluviométrica do Instituto Nacional de Meteorologia (INMET) do município de Barreiras, entre 2000 e 2009, a estação chuvosa se inicia em novembro e apresenta altos índices até março e a estação seca é bem evidenciada entre junho e agosto.

\section{Material e métodos}

Análise espacial e estrutural: Para caracterizar a estrutura espacial de cada fitofisionomia, foi elaborado o diagrama de perfil de vegetação. Em cada área, foi marcado um transecto de cinco por trinta metros (5 x 30m), totalizando $150 \mathrm{~m}^{2}$, sendo amostrados todos os indivíduos lenhosos com diâmetro à altura do peito (DAP) a partir de $3 \mathrm{~cm}$, com altura e diâmetro do caule mensurados. Também foram feitas análises florísticas a fim de comparar as diferenças entre as fitofisionomias amostradas. Os indivíduos amostrados foram coletados, herborizados no laboratório do Instituto de Ciências Ambientais e Desenvolvimento Sustentável/Universidade Federal da Bahia (ICADS/UFBA), enviados para o Herbário do Jardim Botânico do Rio de Janeiro (RB) e as duplicatas para o Herbário do Centro Universitário de Vila Velha, Espírito Santo, onde foram identificadas quanto à espécie. 
Análise temporal: Para realizar uma análise temporal, foram marcados 30 pontos em cada uma das fitofisionomias através de GPS de navegação.Após a marcação dos pontos, foi calculado o Leaf Area Index (Índice de Área Foliar - LAI), o qual representa uma medida de cobertura vegetal e é expresso, segundo Watson (1947), pela razão entre a área foliar do dossel e a área de solo que ele ocupa.

As imagens orbitais que serviram como bases para a elaboração do Índice de Área Foliar pertencem ao sensor Thematic Mapper (TM) localizado no Satélite Landsat-5. Este sensor apresenta resolução espacial nominal de 30m (tamanho físico do pixel), e 7 (sete) bandas espectrais, das quais foram utilizadas duas para a composição do LAI: Vermelho (TM3) e Infravermelho-próximo (TM4). Foram selecionadas imagens dos dias: 19/1/2010 (período chuvoso) e 15/8/2010 (período seco). As imagens foram registradas e corrigidas com base no mosaico de imagens do Satélite Landsat-7 do sensor ETM (Enhaced Thematic Mapper Plus), ortorretificado na NASA, conhecido como Geocover, o qual tem sido amplamente utilizado como informação-base para corrigir as distorções geométricas de imagens em escala de levantamento de recursos naturais (planejamento ambiental).

O processo de correção foi feito através de mapeamento direto, utilizando sete pontos de controle, sendo avaliado o Erro Pontual (EP) e o Erro Quadrático Médio (RMSE). Em seguida, foi realizado o mapeamento inverso utilizando o método "vizinho mais próximo" para manter as características radiométricas originais.

$$
\begin{aligned}
& E P=\sqrt{\left(\mathbf{X}^{\prime}-\mathrm{X}\right)^{2}+\left(\mathrm{Y}^{\prime}-\mathrm{Y}\right)^{2}} \\
& R M S E=\sum \frac{\sqrt{\left(X^{\prime}-X\right)^{2}+\left(Y^{\prime}-Y\right)^{2}}}{N}
\end{aligned}
$$

X', Y' = Projeção cilíndrica UTM das coordenadas “ $x$ ” e “y” da imagem a ser corrigida (bruta);

$\mathrm{X}, \mathrm{Y}=$ Projeção cilíndrica UTM das coordenadas " $\mathrm{x}$ ” e " $y$ ” da imagem referência (Geocover);

$\mathrm{N}=$ Número de pontos de controle coletados na correção geométrica.

Além disso, a correção atmosférica também foi utilizada com o objetivo de mitigar o "espalhamento" nos menores comprimentos de onda, 
e a "absorção", nos maiores comprimentos de onda; conforme o modelo utilizado (FLASH), as imagens foram convertidas em Radiância.

$$
\mathbf{L}_{\lambda}=\mathbf{K}_{\mathbf{i}}+\frac{W_{i}-\mathbf{K}_{\mathbf{i}}}{255} \times N D
$$

$\mathrm{L}_{\lambda}=$ Grandeza radiométrica «Radiância» $\mathrm{w} / \mathrm{m}^{2} / \mathrm{sr} / \mu \mathrm{m}$;

$\mathrm{K}_{\mathrm{i}}=$ Coeficiente de calibração do satélite TM/Landsat-5 - radiância espectral mínima;

$\mathrm{W}_{\mathrm{i}}=$ Coeficiente de calibração do satélite TM/Landsat-5 - radiância espectral máxima;

ND = Imagens em nível digital, que varia conforme a resolução radiométrica.

Para o cálculo do índice de vegetação, LAI, foco principal deste trabalho, o qual tem uma relação direta com a biomassa do ambiente, e representa a razão da área foliar da vegetação fotossintetizante por unidade de área (Braga et al., 2009), as imagens em Radiância foram convertidas para Reflectância com base nos seguintes parâmetros: Latitude e Longitude Central (G M S); Comprimento de onda (central) de cada banda espectral; Altitude do sensor (carga útil do satélite); Data e horário da passagem do satélite; Elevação central da cena; Modelo atmosférico tropical; Modelo de aerossol rural e Visibilidade de aproximadamente $40 \mathrm{~km}$. Vejamos:

$$
\rho_{\lambda}=\frac{\mathbf{L}_{\lambda} \times \pi}{K_{b} \times \cos Z \times I_{t-s}}
$$

$\rho_{\lambda}=$ Reflectância integrada

$\mathrm{L}_{\lambda}=$ Radiância $(\lambda)$

$\mathrm{K}_{\mathrm{b}}=$ Irradiância no topo da atmosfera

cosZ = co-seno do ângulo zenital do sol

$\mathrm{I}_{\mathrm{t}-\mathrm{s}}=$ Inverso do quadrado da distância entre Terra-Sol

e então aplicadas na seguinte fórmula:

$$
L A I=\frac{\ln \left(\frac{0,69-\frac{(1+L) \cdot(T M 4-T M 3)}{(L+T M 4+T M 3)}}{0,59}\right)}{0,91}
$$


Em que:

TM3 = Reflectância do Vermelhoג;

TM4 = Reflectância do Infravermelho-próximo $\lambda$;

$\mathrm{L}=$ Tipo de vegetação local $(0,5)$.

Análise de dados: $\mathrm{O}$ teste de Wilcoxon foi utilizado para testar as diferenças de LAI entre as estações na mesma fitofisionomia, já o teste de Mann-Whitney testava se havia diferenças de LAI entre as fitofisionomias na mesma estação. Todos os testes estatísticos foram realizados utilizando o software BioEstat 5.0.

\section{Resultados}

Análise espacial e estrutural: $\mathrm{O}$ diagrama de perfil da vegetação demonstrou diferenças estruturais entre as fitofisionomias florestais. A floresta estacional semidecidual (Figura 1) possui uma vegetação mais densa e dossel mais fechado, com 67 indivíduos amostrados em $150 \mathrm{~m}^{2}$ $\left(0,46 \mathrm{ind} / \mathrm{m}^{2}\right)$ e com árvores de maior porte cuja média de altura registrada no transecto foi de 12,14m (Desvio padrão $=7,56$ ); o menor indivíduo possuía $3 \mathrm{~m}$ de altura e o maior, $30 \mathrm{~m}$, apresentando um dossel de 20 metros com emergentes de 28 a 30 metros.

A floresta estacional decidual (Figura 2) apresentou uma vegetação menos densa, com 47 indivíduos amostrados $\left(0,31 \mathrm{ind} / \mathrm{m}^{2}\right)$, cuja média de altura foi de 6,52m (Desvio padrão $=2,59$ ), com altura variando entre $2 \mathrm{e}$ $11 \mathrm{~m}$. Além disso, a média de diâmetro dos indivíduos amostrados, na floresta estacional semidecidual, foi de 9,66cm (Desvio padrão $=8,99$ ), com $46 \mathrm{~cm}$ a árvore de maior diâmetro, conferindo então árvores mais grossas e com maior variação que da floresta estacional decidual, em que a média foi de $8,87 \mathrm{~cm}$ (Desvio padrão = 4,92), sendo 22,6 $\mathrm{cm}$ o maior diâmetro, cujo dossel é contínuo e homogêneo, com cerca de $10 \mathrm{~m}$ de altura.

As fitofisionomias também se distinguiram por suas composições florísticas. Na floresta estacional semidecidual, 82\% dos indivíduos amostrados pertenciam às famílias Burseraceae e Annonaceae, representadas pelas espécies Protiumheptaphylum (Aubl.) Marchand e Xylopiasericea (St. Hill) respectivamente. Na floresta estacional decidual, 63,8\% dos indivíduos pertenciam às famílias Combretaceae e Anacardiaceae representadas respectivamente pelas espécies Combretumleprosum (Mart) e Myracrodruonurundeuva (Allemão). 


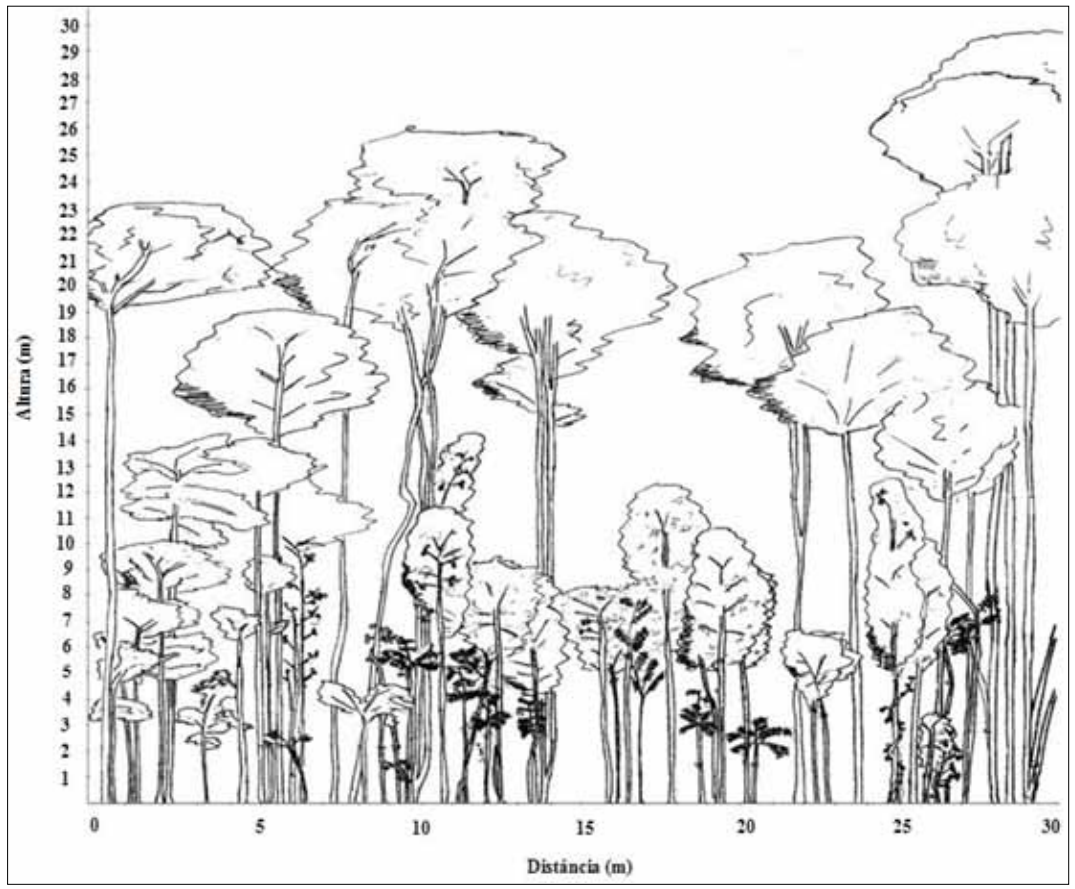

Figura 1 - Perfil de vegetação da floresta estacional semidecidual (Elaborado por Cotias, 2011)

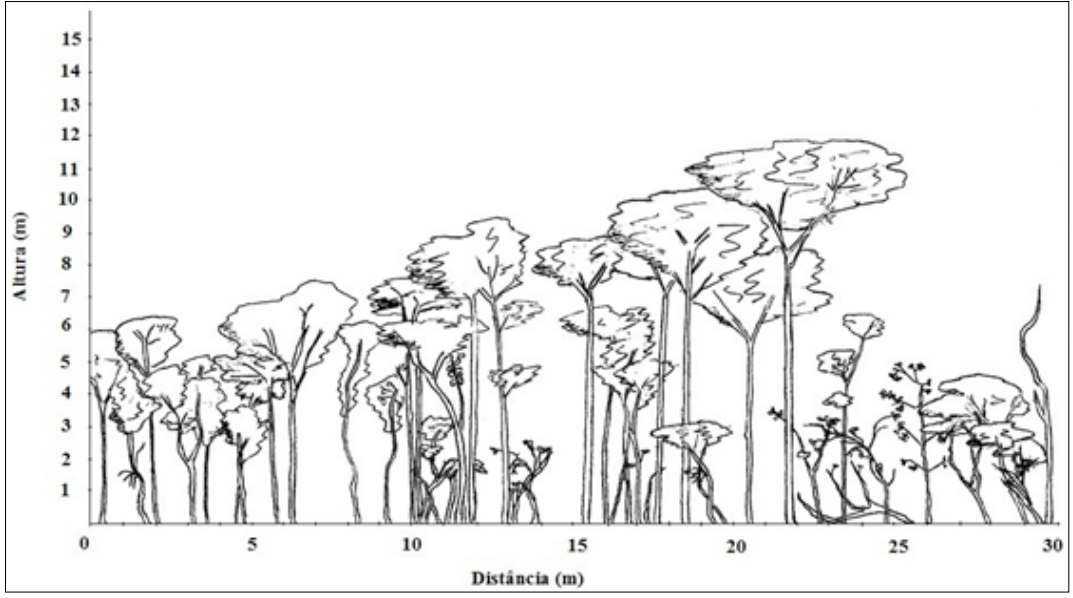

Figura 2 - Perfil de vegetação da Floresta Estacional Decidual (Elaborado por Cotias, 2011) 
Análise temporal: As imagens corrigidas apresentaram um Erro Pontual (EP) variando de 2 a $23 \mathrm{~m}(19 / 01 / 2010)$ e 4 a $25 \mathrm{~m}(15 / 08 / 2010)$ e Erro Quadrático Médio (RMSE) de $15 \mathrm{~m}$ e $17 \mathrm{~m}$, respectivamente. Na inspeção visual, as imagens foram corrigidas geometricamente, quando comparadas à referência Geocover.

Com base nos valores obtidos pelo LAI, foi possível verificar uma variação sazonal significativa (teste de Wilcoxon) da cobertura florestal nas duas fitofisionomias (Figuras 3 e 4). Também foi possível verificar uma diferença significativa (teste Mann-Whitney) na diminuição da cobertura florestal entre as duas fitofisionomias na estação seca (Figuras 3 e 4); a floresta estacional decidual obteve menores valores de LAI na estação seca (Figura 4).O valor médio do LAI, nos pontos amostrados da floresta estacional decidual, foi de 0,0581 , já o valor médio de LAI, na floresta estacional semidecidual, foi de 0,4876 .

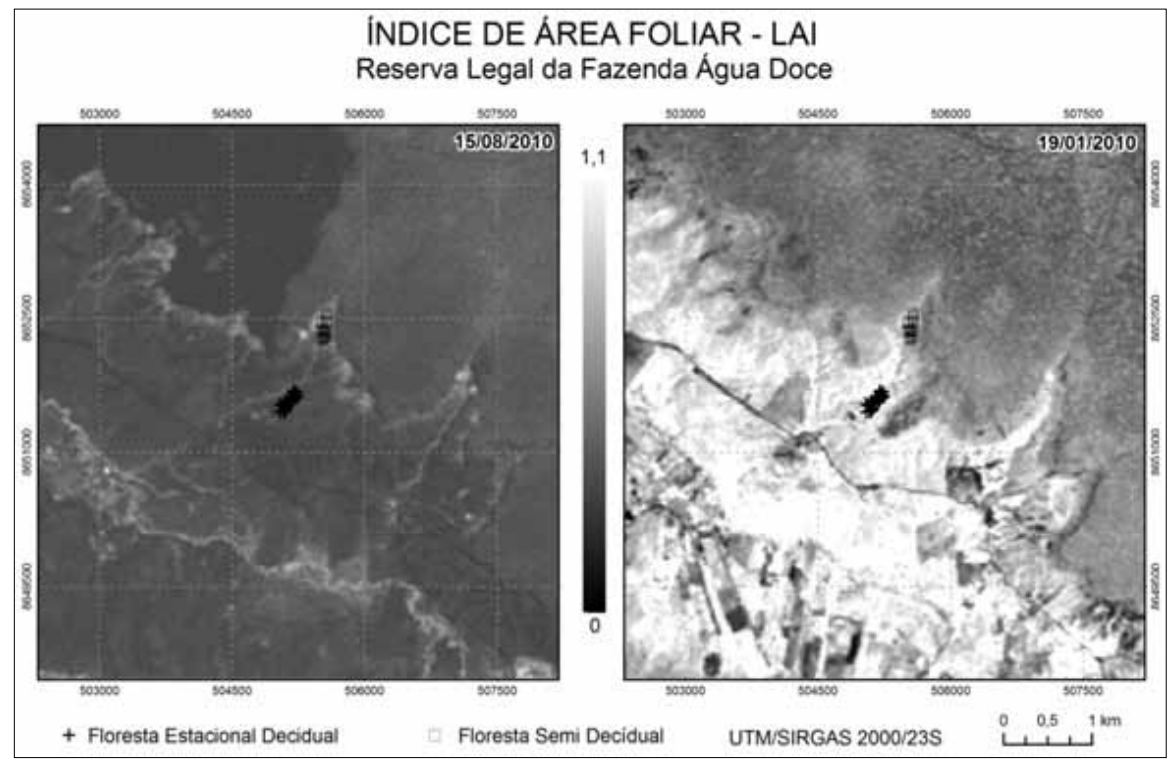

Figura 3 - Índice de Área Foliar (LAl) em virtude da sazonalidade 


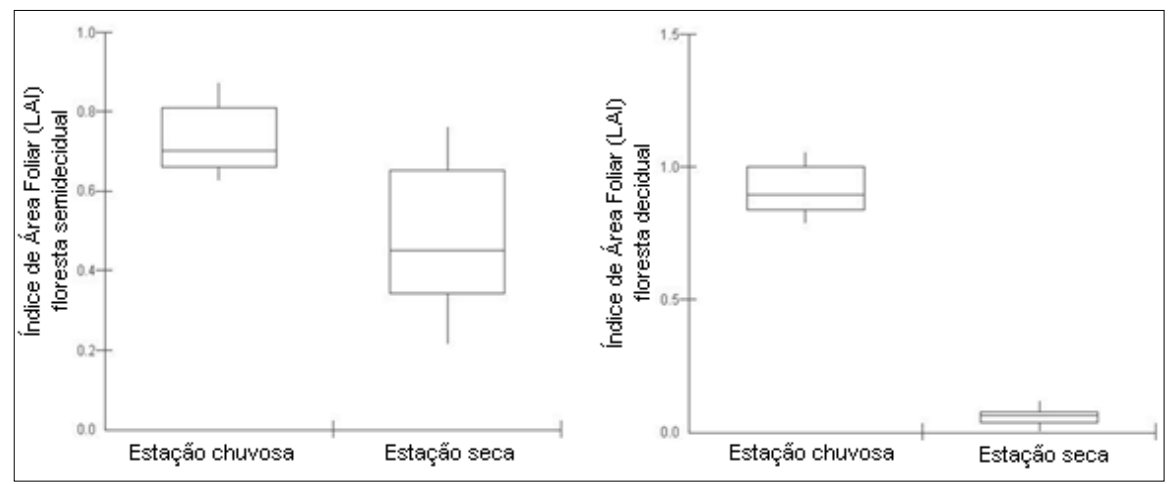

Figura 4 - Variação do Índice de Área Foliar (LAI) na floresta estacional semidecidual e floresta decidual

\section{Discussão}

Por meio das metodologias aplicadas, percebeu-se que as fitofisionomias estudadas possuem diferenças estruturais e florísticas significativas, resultando também em padrões diferenciados em relação à dinâmica temporal.

De uma forma geral, ao longo da paisagem, quando comparadas às áreas que apresentavam diferenças na profundidade e umidade do solo, observou-se uma diferença nos valores de altura e de diâmetro dos indivíduos amostrados. Dessa forma, os menores valores médios de altura, diâmetro e da cobertura de dossel na floresta estacional decidual, quando comparados aos valores obtidos na floresta semidecidual, podem ser explicados pelas características topográficas e edáficas da área de estudo (Figura 2). Ivanauskas e Rodrigues (2000) verificaram a existência de uma relação inversa entre a profundidade do solo e a altura do dossel em remanescentes de floresta estacional decidual no estado de São Paulo. E, segundo Oliveira-Filho e Fluminhan-Filho (1999), aspectos ligados à drenagem e à profundidade do solo condicionam a estrutura da vegetação, alterando aspectos relacionados à altura e à cobertura de dossel.

A variação encontrada na composição florística entre as duas fitofisionomias também pode ser explicada pela variação nas condições ambientais. Para alguns autores, a composição e a profundidade do solo podem ser consideradas como fatores fundamentais no processo de sele- 
ção e estabelecimento de espécies vegetais em escala local (Rodrigues et al., 1989; Araújo, Sampaio, Rodal, 1995).

A presença de espécies indicadoras de solos úmidos na floresta estacional semideciual, como Protiumheptaphylum (Burseraceae) e Xylopiasericea (Annonaceae), assim como a presença de espécies xeromórficas na floresta estacional decidual, como Combretumleprosum (Combretaceae) e Myracrodruonurundeuva (Anacardiaceae), podem corroborar as diferenças ambientais entre as duas fitofisionomias.

O gênero Protium tem sido associado às florestas úmidas (Daly, 1992; Sousa, Guedes, Aparício, 2010). Segundo Silva (2010), este gênero pode indicar trechos mais úmidos dentro de fragmentos de florestas semideciduais. A espécie Xylopiasericea é citada por Lorenzi (1992) como típica de terrenos bem drenados e por Felfili et al., (2000) como indicadora de áreas úmidas.

Já na floresta estacional decidual, a espécie dominante Combretumleprosum é relacionada a áreas mais secas, sendo uma espécie frequente e abundante em levantamentos florísticos realizados em áreas de Caatinga (Souza, Lorenzi, 2008) e de florestas estacionais deciduais (Salis et al., 2004; Lima, 2007; Sccoti et al., 2011). A espécie Myracrodruonurundeuva também possui forte relação com o Bioma Caatinga, sendo frequentemente associada a áreas com alto estresse hídrico (Brandão, 1994; Santos et al., 2007).

Ao apresentarem não só diferenças na altura, no diâmetro e na densidade das árvores, como também na composição florística, as fitofisionomias exibiram, consequentemente, comportamento decidual distinto no que se refere à dinâmica na cobertura vegetal.

Os valores obtidos pelo LAI apontaram para diferenças significativas na cobertura vegetal das fitofisionomias na estação seca e chuvosa, conferindo o caráter decidual das duas fitofisionomias. Entretanto, durante a estação seca, foi verificada uma diferença expressiva entre as proporções de cobertura vegetal nas duas unidades florestais, e o comportamento decidual da floresta estacional decidual foi mais pronunciado corroborando com outros trabalhos (Sano, Ferreira, Huete, 2005; Liesenberg, Ponzoni, Galvão, 2006, 2007) em que a discriminação entre as fitofisionomias é potencializada nesta última estação.

A diferença de LAI, na estação seca, pode ser justificada pela umidade do solo, havendo menor perda foliar na semidecidual por estar condi- 
cionada a menor estresse hídrico. Essa relação foi percebida por Borchert (1994) ao avaliar a umidade do solo, em um trecho de floresta estacional decidual, na Costa Rica e conseguir estabelecer a relação da quantidade de água no solo e perda foliar, concluindo que, quanto maior a umidade, menor será a deciduidade.

Assim, a dinâmica das florestas estudadas está associada a uma série de fatores que vão desde a composição estrutural até as características de topografia e solo, as quais influenciam diretamente na composição florística, atuando como um fator importante na organização e distribuição espacial da vegetação como o observado em outros estudos (Botrel et al., 2002; Martins et al., 2003). Tal fato pode então ter contribuído fortemente com o resultado averiguado neste trabalho.

Embora esses atributos citados permitam a presença dessas florestas nessa região, é importante destacar que a existência delas nos dias atuais, está associada à expansão de outros Biomas, como a Mata Atlântica, em períodos no passado, cujos fatores climáticos favoreceram essa dinâmica. Assim, segundo Felfili (2003), com a retração dos Biomas, alguns encraves permaneceram em locais contendo condições favoráveis, como os tipos de solo, e formando, dessa forma, corredores ligando as florestas estacionais dentro de vários domínios, sendo o caso do presente estudo.

Alguns dos indicadores da forte relação das florestas estacionais dessa região com esse evento histórico, além do registro de espécies típicas de Mata Atlântica, como a Xylopiasericeae Protiumheptaphylum, a floresta semidecidual está associada aos altos índices de zoocoria (mais de $90 \%$ ) conforme foi averiguado em pesquisa realizada sobre fenologia reprodutiva, na mesma área de estudo (Azevedo, 2010).

\section{Considerações finais}

Conclui-se que a delimitação e caracterização dessas áreas de florestas estacionais como unidades de paisagens são fundamentais para o planejamento e desenvolvimento de estratégias de conservação, sobretudo na região Oeste da Bahia, onde ainda são encontrados poucos fragmentos, os quais podem desempenhar um papel fundamental na manutenção da biodiversidade regional, atuando como sítio de espécies da fauna e flora adaptadas a ambientes úmidos, podendo influenciar na oferta de recursos ou como áreas de refúgio e de corredor de dispersão para a fauna. 


\section{Referências}

AGUIAR, Ludmilla Moura de Souza; MACHADO, Ricardo Bomfim; MARINHOFILHO, Jader. A diversidade biológica do Cerrado. In: AGUIAR, L. M. S.; CAMARGO, A. J. (Eds.). Cerrado: ecologia e caracterização. Brasília, DF: Embrapa Cerrados, 2004. p. 17-40.

ARAÚJO, Elcida de Lima; SAMPAIO, Everardo V. S. B.; RODAL, Maria Jesus Nogueira. Composição florística e fitossociológica de três áreas de Caatinga de Pernambuco. Revista Brasileira de Biologia, v. 55, n. 4, p. 595-607, 1995.

AZEVEDO, Geide Moreira. Fenologia reprodutiva de espécies arbóreas em áreas de Floresta Estacional Decidual e Semidecidual, Oeste da Bahia. 2010. 46 f. Monografia (Trabalho de conclusão do curso de Ciências Biológicas) Universidade Federal da Bahia, Barreiras, 2010.

BAKER, Patrick J. e WILSON, Jeremy S. A quantitative technique for the identification of canopy stratification in tropical and temperate forests. Forest Ecology and Management, v. 127, 2000. p. 77-86.

BORCHERT, Rolf. Soil and Stem Water Storage Determine Phenology and Distribution of Tropical Dry Forest Trees. Ecology, v. 75, n. 5, p. 1437-1449, 1994.

BOTREL, Rejane T. et al. Influência do solo e topografia sobre as variações da composição florística e estrutura da comunidade arbóreo-arbustivo de uma Floresta Estacional Semidecidual em Ingaí, MG. Revista Brasileira de Botânica, v. 25, p. 195-213, 2002.

BRAGA, C. C. et al. Determinação do albedo e índice de área foliar usando o sensor TM/Landsat 5. In: Anais do XIV Simpósio brasileiro de sensoriamento remoto, 2009, Natal -RN. XIV Simpósio Brasileiro de Sensoriamento Remoto. São José dos Campos, 2009. v. 1. p. 935-942.

BRANDÃO, Mitzi. Área Mineira do Polígono das Secas/Cobertura Vegetal. Informe Agropecuário, v. 17, n. 181, 1994.

CAMPOS, José Eloi Guimarães; DARDENNE, Marcel Auguste. Estratigrafia e Sedimentação da Bacia Sanfranciscana: Uma Revisão. Revista Brasileira de Geociências, v. 27, n. 3, p. 269-282, 1997.

COTIAS, Fernando dos Anjos. Perfil de vegetação. 2011. 2 desenhos, 30 x 30 cm.

DALY, Douglas C. New taxa and combinations in ProtiumBurm.f. Studies in neotropical Burseraceae VI. Brittonia, v. 44, n. 3, p. 280-299, 1992.

EITEN, George. The cerrado vegetation of Brazil. Botanical Review, v. 38, p. 201341, 1972.

FELFILI, Jeanine Maria; SCARIOT, Aldicir; SOUZA-SILVA, José Carlos. Cerrado: ecologia, biodiversidade e conservação. Brasília: Ministério do Meio Ambiente, v. 1, 2005. 439 p.

FELFILI, Jeanine Maria. Fragmentos de florestas estacionais do Brasil Central: diagnóstico e proposta de corredores ecológicos. In: COSTA, Reginaldo Brito da 
(Org.). Fragmentação florestal e alternativas ao desenvolvimento rural na Região Centro-Oeste. Campo Grande: UCDB, 2003. p. 139-160.

FELFILI, Jeanine Maria et al. Recuperação de matas de galeria. Brasília, DF: Embrapa, 2000. 45p.

IBGE, Instituto Brasileiro de Geografia e Estatística. Manual Técnico da Vegetação Brasileira. Rio de Janeiro: IBGE, 1992. 92p.

IVANAUSKAS, Natália Macedo; RODRIGUES, Ricardo Ribeiro. Florística e fitossociologia de remanescentes de floresta estacional decidual em Piracicaba, São Paulo. Revista Brasileira de Botânica, São Paulo, v. 23, n. 3, p. 291-304, 2000.

LIESENBERG, Veraldo; PONZONI, Flávio Jorge; GALVÃO, Lênio Soares. Discriminação espectral de algumas fitofisionomias de Cerrado brasileiro através de dados multitemporais do sensor MODIS/TERRA. In: XIII Simpósio Brasileiro de Sensoriamento Remoto, 2007, Florianópolis. Anais do XIII Simpósio Brasileiro de Sensoriamento Remoto, 2007.

LIESENBERG, Veraldo; GALVÃO, Lênio Soares; PONZONI, Flávio Jorge. Variations in reflectance with seasonality and viewing geometry: implications for classification of Brazilian savanna physiognomies with MISR/Terra data. Remote Sensing of Environment, v. 107, n. 2, p. 276-286, 2006.

LIMA, Jacira Rabelo et al. Estrutura da floresta estacional decidual montana (mata seca) da RPPN Serra das Almas, Ceará. Revista Brasileira de Biociências (Impresso), v. 5, p. 438-440, 2007.

LOPES, Clarissa Gomes Reis. Relações florísticas e estruturais entre fragmentos de florestas secas e úmidas (Floresta Atlântica), Nordeste do Brasil. Dissertação (Mestrado em Botânica) - Universidade Federal Rural de Pernambuco, Recife, 2007. $85 \mathrm{f}$.

LORENZI, Harri. Árvores brasileiras: manual de identificação e cultivo de plantas arbóreas nativas do Brasil. Nova Odessa: Instituto Plantarum, 1992. 352p.

MACHADO, Ricardo Bomfim et al. Caracterização da Fauna e Flora do Cerrado. In: FALEIRO, Fábio; FARIAS NETO, Austecílnio Lopes (Orgs.). Savanas - desafios e estratégias para o equilíbrio entre sociedade, agronegócio e recursos naturais. Planaltina-DF: Embrapa Cerrados, 2008. p. 285-300.

MARTINS, Sebastião Venâncio et al. Distribuição de espécies arbóreas em um gradiente topográfico de Floresta Estacional Semidecidual em Viçosa, MG. Scientia Forestalis, v. 64, p. 172-181, 2003.

MUELLER, Charles. C.; MARTHA JÚNIOR, Geraldo. A agropecuária e o desenvolvimento socioeconômico recente do Cerrado. In: FALEIRO, F. G.; FARIAS NETO, A. L. (Orgs.). Savanas: desafios e estratégias para o equilíbrio entre sociedade, agronegócio e recursos naturais. Planaltina: Embrapa Cerrados, 2008. cap. 4, p. $105-172$

OLIVEIRA-FILHO, Ary T.; FLUMINHAN-FILHO, Miguel. Ecologia da vegetação do Parque Florestal Quedas do Rio Bonito. CERNE, v. 5, n. 2, p. 51-064, 1999. 
RAMOS, Maria Cristina; PELLENS, Roseli; LEMOS, Lilian Cristiane. Perfil e florística de dois trechos de mata litorânea no Município de Maricá-RJ. Acta Botânica Brasilica, v. 15, p. 321-334, 2001.

RATTER, James Alexander; BRIDGEWATER, Samuel; RIBEIRO, José Felipe. Analysis of the floristic composition of the Brazilian Cerrado vegetation III: comparison of the woody vegetation of 376 areas. Edinburgh Journal of Botany, Cambridge, v. 60, p. 57-109, 2003.

REIS, Simony Lopes da Silva et al. Identificação de áreas degradadas no Oeste da Bahia através de técnicas de geoprocessamento. In: XII Encontro de Geógrafos da América Latina. Caminando en una América Latina em transformación. Montevideo: EasyPlanners, 2009. v. XII.

RIBEIRO, José Felipe; WALTER, Bruno Machado Teles. Fitofisionomias do Bioma Cerrado. In: SANO, S. M.; ALMEIDA, S. P. Cerrado: ambiente e flora. Embrapa Cerrados, DF. 1998. cap. 3, p. 87-166.

RODRIGUES, Ricardo Ribeiro et al. Estudo florístico e fitossociológico em um gradiente altitudinal de mata estacional mesófila semidecídua, na Serra do Japi, Jundiaí, SP. Revista Brasileira de Botânica, São Paulo, v. 12, p. 71-84, 1989.

SALIS, Suzana Maria et al. Fitossociologia de remanescentes de floresta estacional decidual em Corumbá, Estado do Mato Grosso do Sul, Brasil. Revista Brasileira de Botânica, v. 27, n. 4, p. 671-684, 2004.

SANO, Edson E. et al. Mapeamento semidetalhado do uso da terra do Bioma Cerrado. Pesquisa Agropecuária Brasileira, v. 43, n. 1, p. 153-156, 2008.

SANO, Edson E.; FERREIRA, Laerte Guimarães.; HUETE, Alfredo R. Synthetic Aperture Radar (L-band) and optical vegetation indices for discriminating the Brazilian savanna physiognomies: a comparative analysis. Earth Interactions, v. 9, n. 15, p. 1-15, 2005.

SANTOS, Rubens Manoel et al. Riqueza e similaridade florística de oito remanescentes florestais no norte de Minas Gerais. Revista Árvore, v. 33, n. 1, 2007.

SCCOTI, Marta Silvana Volpato et al. Mecanismos de regeneração natural em remanescente de Floresta Estacional Decidual. Revista Ciência Florestal, v. 21, n. 3, p. 459-472, 2011.

SILVA, Izabel Cristina. Caracterização fisionômica de fragmentos vegetacionais do distrito de Rubião Júnior, município de Botucatu, São Paulo. Dissertação (Mestrado em Botânica) - Universidade Estadual Paulista, Botucatu, 2010, $116 \mathrm{f}$.

SOUSA, Madson Alan Rocha; GUEDES, Marcelino Carneiro; APARÍCIO, Perseu da Silva. Fitossociologia de um trecho de floresta ombrófila densa submontana na estação ecológica do Jari, Almeirim, Pará. In: 61ํㅜㄷㅗ. Congresso Nacional de Botânica, 2010, Manaus, AM. Diversidade vegetal brasileira - conhecimento, conservação e uso, 2010.

SOUZA, Vinicius Castro; LORENZI, Harri. Botânica Sistemática: guia ilustrado para identificação das famílias de fanerógamas nativas e exóticas no Brasil, baseado em APG II. 2. ed. Nova Odessa, SP: Instituto Plantarum, 2008. p. 217. 
WATSON, Don J. Comparative physiological studies on growth of field crops: I. Variation in net assimilation rate and leaf area between species and varieties, andwithin and between years. Annalsof Botany, v. 11, p. 41-76, 1947.

Daiany Caroline Joner - Licenciada em Ciências Biológicas e graduanda de Bacharelado em Ciências Biológicas pela Universidade Federal da Bahia.

Luci Ferreira Ribeiro - Possui doutorado e mestrado pela Universidade Federal de Pernambuco. Graduação pela Universidade Federal do Piauí. Atualmente é professora da Universidade Federal da Bahia.

Pablo Santana Santos - Doutorando em Geografia pela Universidade Federal de Goiás. Possui mestrado em Sensoriamento Remoto pelo Instituto Nacional de Pesquisas e graduação em Engenharia Agronômica da Universidade Estadual de Santa Cruz. Atualmente é Professor Assistente II pela Universidade Federal da Bahia. 